MIDAS

Museus e estudos interdisciplinares

$7 \mid 2016$

Varia

\title{
Clara Frayão Camacho - Redes de Museus e Credenciação: Uma Panorâmica Europeia
}

\section{Graça Filipe}

\section{(2) OpenEdition}

\section{Journals}

\section{Edição electrónica}

URL: http://journals.openedition.org/midas/1058

DOI: $10.4000 /$ midas. 1058

ISSN: 2182-9543

\section{Editora:}

Alice Semedo, Paulo Simões Rodrigues, Pedro Casaleiro, Raquel Henriques da Silva, Ana Carvalho

\section{Refêrencia eletrónica}

Graça Filipe, "Clara Frayão Camacho - Redes de Museus e Credenciação: Uma Panorâmica Europeia », MIDAS [Online], 7 | 2016, posto online no dia 28 novembro 2016, consultado no dia 25 setembro 2020 URL : http://journals.openedition.org/midas/1058; DOI : https://doi.org/10.4000/midas.1058

Este documento foi criado de forma automática no dia 25 setembro 2020.

\section{(c) (i) (2) (2)}

Midas is licensed under a Creative Commons Attribution-NonCommercial-ShareAlike 3.0 International License 


\title{
Clara Frayão Camacho - Redes de Museus e Credenciação: Uma Panorâmica Europeia
}

\author{
Graça Filipe
}

\section{REFERÊNCIA}

Camacho, Clara Frayão. 2015. Redes de Museus e Credenciação: Uma Panorâmica Europeia.

Coleção Estudos de Museus. Lisboa: Caleidoscópio e Direção-Geral de Património

Cultural. 431 páginas, ISBN: 978-989-658-337-8.

1 O livro de Clara Frayão Camacho é resultado do seu trabalho de tese de doutoramento (Universidade de Évora), que teve por objeto de estudo o historial, a caracterização e a comparação dos sistemas de credenciação de nove países que integram a União Europeia - Espanha, França, Irlanda, Itália, Letónia, Países Baixos, Polónia, Portugal e Reino Unido - entre 1985 e 2010 e que para lá deste período dedica um capítulo de abordagem comparativa às mudanças operadas entre 2010 e 2013. Para além de identificar algumas limitações de acesso a fontes, que naturalmente condicionaram a delimitação do terreno de pesquisa e a configuração daquele campo geográfico, a autora justifica a escolha de países de incidência do seu estudo em função quer da sua proximidade de escala e de estrutura em relação a Portugal (apesar da diversidade quanto à dimensão e à configuração territorial e administrativa), quer de critérios de representatividade geográfica intraeuropeia.

Descrevendo-nos uma metodologia centrada na investigação histórica, para o estudo que situa no domínio da Museologia, Clara Frayão Camacho informa ter ainda recorrido a outros contributos disciplinares, dos quais destaca os da Ciência Política, do Direito e da Sociologia (p. 13).

o livro é composto de cinco partes, incluindo a «Introdução» e as "Conclusões», seguidas das notas, da lista de siglas e acrónimos, das fontes e bibliografia e, finalmente, 
dos agradecimentos. A opção editorial de sequenciar as notas em páginas separadas do texto em meu entender dificulta a sua leitura.

4 A «Introdução» contextualiza o tema de estudo de Clara Frayão Camacho, do ponto de vista da história contemporânea recente dos museus europeus, e apresenta as razões do seu interesse para a autora e da ligação com experiências antecedentes, tanto na esfera profissional, como de âmbito académico. Importa salientar o reconhecimento de uma «observação implicada da realidade portuguesa» (p. 9), aspeto que, a meu ver, consolida e adensa a análise apresentada e a abordagem comparativa com outras realidades.

As três partes fundamentais do livro, e do corpo da tese de doutoramento da autora, são intitulados respetivamente: «Estado da Arte», «Perspetiva Diacrónica» e «Perspetiva Comparada».

6 A revisão de literatura ou «Estado da Arte» parte de um quadro conceptual definido pela Museologia, simultaneamente atento à evolução e às tendências recentes das políticas públicas neste domínio, abarcando a «Noção de Credenciação», as «Noções de Sistema e de Rede», as «Visões Europeias» e os «Olhares Nacionais». Apesar da bibliografia ser incidente no período cronológico apontado (1985-2010), Clara Frayão Camacho refere ter contemplado as obras que proliferaram nos anos subsequentes, até à redação do trabalho (2013), sobre os temas em estudo. A autora considera no geral que a bibliografia sobre credenciação, sistemas e redes de museus na Europa, maioritariamente proveniente da esfera profissional dos museus, principalmente assente em atas, periódicos e algumas dissertações, é fragmentada, dado que poucas pontes se estabelecem entre a credenciação e o tema dos sistemas e das redes de museus, mas, como aspeto favorável ao seu próprio horizonte de investigação, salienta a multidisciplinaridade das abordagens, com olhares provenientes da Museologia, da História, da Sociologia, do Direito e da Economia (p. 21).

7 A parte do livro subordinada à «Perspetiva Diacrónica (1985-2010)» segue, como indica Clara Frayão Camacho, uma abordagem histórica, de base cronológica, para o período em análise. Começa-se por um importante capítulo de contextualização e de compreensão dos antecedentes, nomeadamente no espaço extraeuropeu, remontando à década de 1950, com as designadas «Raízes Norte-Americanas», e trazendo ao nosso conhecimento uma primeira tentativa britânica, mal sucedida nos anos de 1970, praticamente ignorada, ou esquecida. A esse capítulo segue-se a caracterização dos percursos e das realidades nos nove países estudados, a cada qual dedicando um capítulo distinto, à exceção dos casos da Polónia e da Letónia, examinados conjuntamente. As balizas cronológicas definidas reportam-se à data de criação do Sistema Espanhol de Museus (1985) e ao ano em que Clara Frayão Camacho iniciou o seu estudo (2010). Saliento o valor específico da síntese respeitante ao caso português, assim como o interesse dos apontamentos críticos do capítulo "Credenciação e Organização em Rede: a Rede Portuguesa de Museus» (pp. 192-219), em relação ao qual a autora assume a contaminação do exercício reflexivo pela predominância do conhecimento empírico (p. 192).

8 A quarta parte do livro, intitulada «Perspetiva Comparada», visa relacionar e comparar sincronicamente as realidades anteriormente estudadas, estabelecendo o ano 2009 como referencial, portanto numa fase imediatamente antecedente ao período de elaboração do trabalho e também caracterizado por significativas mudanças de contextos institucionais nacionais e de alterações orgânicas nos campos patrimonial e museológico, com incidência nos sistemas de credenciação dos países em estudo 
(2010-2013). Em termos metodológicos, Clara Frayão Camacho traça a sua análise comparativa em três fases, começando pelos objetivos e âmbitos administrativos nacionais, passando às medidas e aos meios (excluídos porém os meios financeiros) e por fim abordando os resultados.

9 Saliento a notável fluidez narrativa com que Clara Frayão Camacho apresenta as duas partes que considero centrais no seu livro, dedicadas à perspetiva diacrónica e à perspetiva comparativa, apesar da complexidade das matérias nelas tratadas. A sua sistematização em subcapítulos, que não consta do índice, com títulos expressivos inerentes à caracterização dos ciclos evolutivos, das singularidades dos processos descritos e dos quadros conceptuais de análise, contribuem significativamente para a sua compreensão e facilitam-nos o ritmo de leitura.

10 No capítulo da «Conclusão», Clara Frayão Camacho identifica aqueles que considera - e há que reconhecê-los - como três contributos principais do seu trabalho para o conhecimento e a compreensão do mapa europeu de 25 anos de credenciação, de sistemas e de redes nacionais de museus: «a perspetivação diacrónica da evolução destas realidades e a fixação das etapas da credenciação» - anos 1980; anos 1990-2000 e em torno de 2009-2010 -, «a apresentação e a caracterização de um panorama polarizado» e "a parametrização das relações entre a credenciação e os sistemas e as redes nacionais de museus» (p. 347).

11 Chamando a atenção para os ciclos longos de gestação da credenciação e para o equilíbrio entre influências exógenas e endógenas nesses ciclos, Clara Frayão Camacho também confere evidência à inscrição constante dos sistemas de credenciação «na oficialização ou na expansão das políticas públicas para museus», processos que «confluíram nos momentos em que os órgãos governamentais quiseram abarcar a totalidade das realidades museológicas nacionais e não apenas os museus na órbita das suas próprias tutelas» (p. 349) e refuta a ideia apontada no Código Deontológico do Conselho Internacional de Museus (ICOM) de 2009, de uma realidade em geral marcada pela inconsistência dos quadros legislativos no domínio museal (p. 350). Alerta, porém, para a suposta dualidade entre leis de museus e sistemas de credenciação, apresentando-nos um panorama bem mais complexo e frequentemente com realidades híbridas.

12 Como a própria autora refere, esta obra deve interessar a todos os profissionais de museus, entre os quais tem sido até ao presente insuficiente a circulação e o acesso à informação sobre as temáticas tratadas no livro em apreço, assim como convoca a atenção dos investigadores que em vários âmbitos disciplinares pretendam abordar outras realidades e contextos ou discutir e aprofundar os casos de estudo apresentados e prosseguir a análise da sua evolução, sempre que possível alargando o espectro geográfico de conhecimento para que Clara Frayão Camacho trouxe importantes contributos metodológicos, de análise e de comparação de processos. Por outro lado, e na prática, a autora aponta alguns potenciais desafios, por exemplo em torno da emergente problemática da programação das redes de museus e, em particular, da reprogramação da Rede Portuguesa de Museus, pressupondo que para tal teria de ser especificamente desenhado «um programa de investigação alternativo e mais atento a outras componentes da política pública para o setor museológico» (p. 12).

13 Da natureza museológica deste trabalho e do quadro de reflexões que acompanham o historial e a sistemática caracterização dos ciclos de gestação e dos resultantes regimes de credenciação de museus em nove países europeus, e contrapondo-se à padronização 
da instituição museal, emergem também outras questões, de fundo, como o fenómeno da sua incessante multiplicação e a busca de novos conceitos de museu, sob o prisma da diversidade de definições e de incessantes reinvenções, inerentes às tentativas de adaptação aos contextos, em que principalmente se constroem missões singulares e razões de existência de museus supostamente irrepetíveis no tempo e no espaço social.

\section{AUTOR}

\section{GRAÇA FILIPE}

Instituto de História Contemporânea, Faculdade de Ciências Sociais e Humanas, Universidade Nova de Lisboa, Portugal, gracafilipe@mail.telepac.pt 